\section{Effect of Dipyridamole and Aspirin in Thrombotic Microangiopathy}

\author{
M. GIROMINI, C. A. BOUVIER, R. DAMI, \\ M. DENIZOT, M. JEANNET
}

British Medical fournal, 1972, 1, 545-546

Since the first description of thrombotic thrombocytopenic purpura by Moschcowitz (1925) some progress has been made in understanding the pathogenesis of the disease. The condition is closely related to thrombotic microangiopathy described by Symmers (1952) and to the haemolytic-uraemic syndrome first described in the child by Gasser et al. (1955) and in the adult by Dunea et al. (1966).

\section{Case Report}

A 26-year-old physiotherapist was apparently healthy until January 1971, when he complained of progressive weakness. A few days before admission to hospital he had pain in the lumbar region, headache, red urine, and prolonged bleeding of a small wound. In

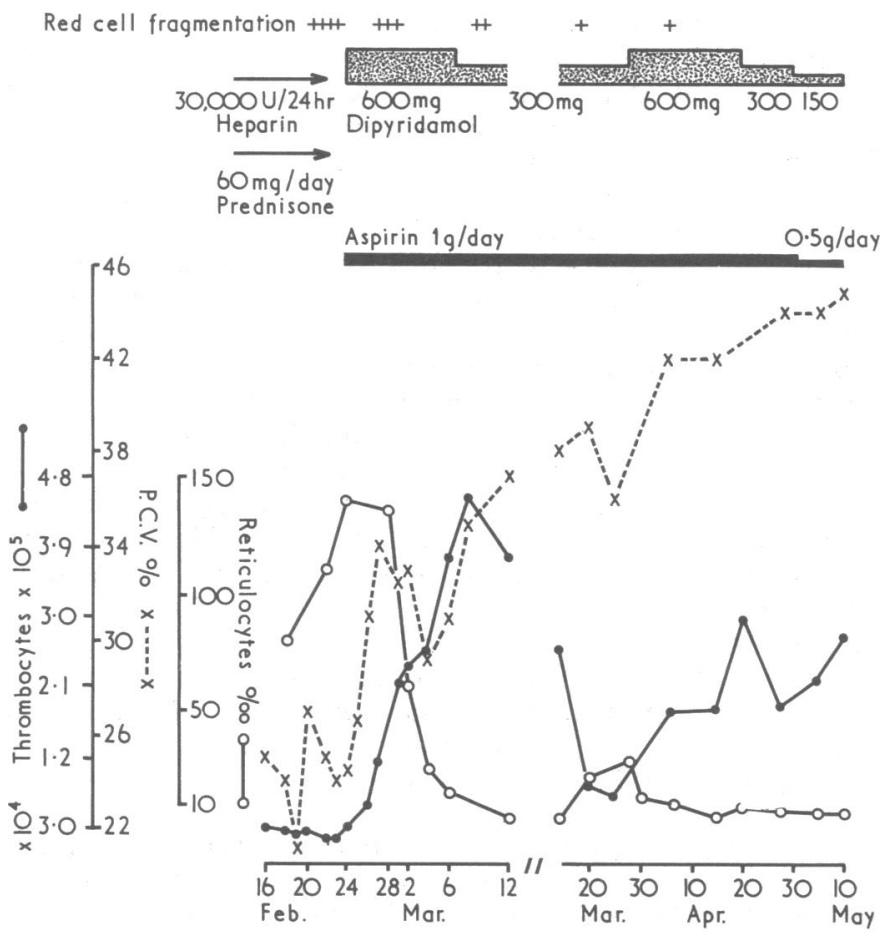

Clinical course during treatment.

Department of Medicine, Hôpital Cantonal, Geneva, Switzerland M. GIROMINI, M.D., Chief, Medical Therapeutic Clinic C. A. BOUVIER, M.D., Head, Haemostasis Unit R. DAMI, M.D., Assistant, Medical Therapeutic Clinic M. DENIZOT, M.D., Assistant, Medical Policlinic M. JEANNET, M.D., Head, Blood Transfusion Unit hospital he was pale, subicteric, and had small petechiae on his legs. Blood pressure was $160 / 70 \mathrm{~mm} \mathrm{Hg}$. Findings on physical examination were otherwise normal. Blood urea nitrogen was 14.5 $\mathrm{mg} / 100 \mathrm{ml}$, and creatinine $1 \cdot 1 \mathrm{mg} / 100 \mathrm{ml}$. A total of $1,100 \mathrm{ml}$ of urine was passed in the first 24 hours. Proteinuria was present in traces, and urinary sediment contained numerous red cells and blood-cell casts. The blood picture was characterized by anaemia (a packed cell volume $24 \%$, haemoglobin $9.1 \mathrm{~g} / 100 \mathrm{ml}$ ). The haemolytic origin of the anaemia was shown by the presence of traces of haemoglobin in the urine, absence of haptoglobin in the serum, and raised non-conjugated bilirubin and iron in the serum. Reticulocyte count was $7.8 \%$, leucocytes were normal, but thrombocytes were down to $22,000 / \mathrm{mm}^{3}$. Complete studies of coagulation factors disclosed no abnormality.

Peripheral blood smears showed pronounced anisocytosis and fragmentation of erythrocytes. Liver function studies showed no abnormalities apart from the raised bilirubin.

These findings were judged sufficiently characteristic for thrombotic microangiopathy to be diagnosed and renal biopsy was not attempted. Intravenous heparin therapy (30,000 units/24 $\mathrm{hr}$ ) was started immediately, and as the clinical picture remained unchanged prednisone $(60 \mathrm{mg} / 24 \mathrm{hr}$ ) was added after five days (see Chart). Haemolysis and thrombopenia persisted and signs of liver damage appeared (SGOT 88 units, SGPT 67 units). After a week the heparin and prednisone therapy was discontinued and the patient was treated with aspirin $(1 \mathrm{~g} /$ day $)$ and dipyridamole $(600$ $\mathrm{mg} /$ day. Thrombopenia improved rapidly and three days later the thrombocyte count was normal. Haemolytic anaemia improved progressively and fragmented red cells gradually disappeared. An attempt to decrease dipyridamole to $300 \mathrm{mg} /$ day led to a rapid fall in platelet count and packed cell volume, but both returned quickly to normal once the initial dose was reinstituted. Three months after admission dipyridamole was gradually withdrawn, and eight months later he was still in excellent health with a normal blood picture and normal renal and liver function.

\section{Comment}

Thrombotic microangiopathy is characterized by haemolytic anaemia and thrombopenia. The typical histological changes are fibrin deposition in arterioles and glomerular capillaries, with frequent occlusion of the vessels. This lesion has been shown to be directly responsible for the red cell fragmentation and haemolysis (Bull and Brain, 1965). Thrombopenia is probably secondary to the consumption of platelets in the fibrin thrombi.

Corticosteroids and heparin treatment are the only therapeutic measures generally applied. The use of drugs which inhibit platelet adhesiveness and aggregation such as aspirin and dipyridamole has been advocated in association with anticoagulants in acute glomerulonephritis, malignant hypertension, and also in kidney transplant rejection (Kincaid-Smith et al., 1970). Recently it has also been shown that dipyridamole is able to prevent platelet consumption and systemic emboli resulting from prosthetic heart valves (Harker and Schlichter, 1970). Aspirin has no corrective effect on platelet survival when given alone but was found to have a potentiating effect on dipyridamole.

In the present case we initiated treatment with aspirin and dipyridamole with the hope of preventing platelet consumption after the failure of heparin and prednisone therapy. The effect of the treatment was extremely rapid, resulting in a normal platelet count in three days. The haemolytic syndrome improved more gradually (see Chart).

Because the treatment of thrombotic microangiopathy with aspirin and dipyridamole is simple to handle and without 
serious risk, in our opinion it deserves a more extensive trial. It may represent a new way to induce remissions in this often fatal condition.

We are grateful to Boehringer (Basel) and Dr. Karl Thomae (Biberach a/Riss) for providing us with dipyridamole (Persantin).

Requests for reprints should be addressed to Dr. M. Giromini, Medical Therapeutic Clinic, Hôpital Cantonal, 1211 Geneva 4, Switzerland.

\section{References}

Bull, B. S., and Brain, M. C. (1968). Proceedings of the Royal Society of Medicine, 61, 1134

Dunea, G., Muehrke, R. C., Nakamoto, S., and Schwartz, F. D. (1966). American fournal of Medicine, 41, 1000.

Gasser, C., Gautier, E., Steck, A., Siebermann, R. E., and Oechlin, R (1955). Schweizerische medizinische Wochenschrift, 85, 905.

Harker, L. A., and Schlichter, S. J. (1970). New England fournal of Medicine, 283, 1302 .

Kincaid-Smith, P., Laver, M. C., and Fairley, K. F. (1970). Medical Fournal of Australia, 3, 145.

Moschcowitz, E. (1925). Archives of Internal Medicine, 36, 89.

Symmers, W. St. C. (1952). British Medical fournal, 2, 897.

\section{Splenic Abscess due to Salmonella agona}

\section{M. SHARR}

\section{British Medical fournal, 1972, 1, 546}

Splenic abscess is an uncommon surgical problem. Reid and Lang (1954) quoted an incidence of 67 out of 16,514 necropsies $(0.4 \%)$. In only one of these cases was the correct diagnosis made before death.

The following case is unusual in that Salmonella agona, which until recently was a very uncommon salmonella serotype in Britain, was the cause of a very large splenic abscess.

\section{Case Report}

The patient, a 22-year-old college student, was admitted to hospital on 5 January 1971. One month previously she had developed an influenza-like illness with general malaise, cough, and purulent sputum. At the same time some of her colleagues had developed a gastrointestinal illness which occurred after a college supper dance. The patient, however, did not attend the function and did not have any gastrointestinal symptoms at that time. She continued to remain unwell and febrile with rigors and symptoms of a chest infection. Two weeks before her admission to hospital she began to develop left-sided abdominal pain which was later accompanied by swelling of the left hypochondrium and diarrhoea. These symptoms persisted up to her admission. There was no notable past medical history.

On examination she appeared thin, ill-looking, and pale. Temperature was $103^{\circ} \mathrm{F}\left(39.4^{\circ} \mathrm{C}\right)$, pulse $120 / \mathrm{min}$, regular, and blood pressure $130 / 80 \mathrm{~mm} \mathrm{Hg}$. There was dullness on percussion of the chest, and breath sounds were reduced at the left base. On palpation a very large, fluctuant tender mass was occupying the whole of the left hypochondrium. Rectal examination was negative. A provisional diagnosis of intra-abdominal abscess was made.

Investigations were: haemoglobin $10.4 \mathrm{~g} / 100 \mathrm{ml}$; M.C.H.C. 32.4 $\mathrm{g} / 100 \mathrm{ml}$; white blood count $20,400 / \mathrm{mm}^{3}$, with $86 \%$ neutrophils; E.S.R. $68 \mathrm{~mm} / \mathrm{hr}$. Several blood cultures were negative. Chest and abdominal $x$-ray pictures confirmed the presence of a mass in the left hypochondrium. A clinical diagnosis of a splenic abscess was made. On 6 January under a general anaesthetic, an incision was made over the maximal area of fluctuation and 2.51 . of foul yellow pus was obtained. After drainage this was seen to have come from an enlarged spleen that was thinned owing to distension by the pus. Tube drainage was inserted.

Bacteriological examination of the pus yielded a profuse growth of Salm. agona. Examination of the faeces showed the same organism to be present. Chemotherapy with ampicillin was started. Although pus continued to discharge through the drainage tube the patient's clinical condition slowly improved. On 22 January, under a general anaesthetic, splenectomy was performed through an upper midline incision and $600 \mathrm{~g}$ of spleen was re-

Southampton Group of Hospitals

M. M. SHARR, M.R.C.P., F.R.C.s., Surgical Registrar moved. After this her progress was uneventful and she was finally discharged from hospital on 15 February, though faeces still showed a scanty growth of Salm. agona to be present. At outpatient review on 12 March the wound was fully healed, she had gained weight, and she felt very well. A faeces culture was still positive for Salm. agona.

\section{Comment}

Salm. agona was until recently a very uncommon salmonella serotype, although in the nine months preceding April 1971 450 cases of infection were reported (British Medical fournal, 1971), most of these being sporadic cases with a few small outbreaks and one large outbreak which occurred after a college supper dance. Although the patient did not attend the function associated with this large outbreak her initial infection may have been related to it.

Many different organisms have in the past been known to be the cause of splenic abscess.

Vita et al. (1969) reported a case of splenic abscess due to Salm. typhimurium which they treated similarly-that is, by splenotomy and drainage followed by splenectomy.

Splenic abscess is a potentially dangerous condition. McSherry and Dineen (1962) reported 100\% mortality in 12 cases. At necropsy nine patients were found to have generalized pyaemia. Of the remaining three, one had a solitary splenic abscess and a splenocolic fistula from a carcinoma of the colon, one (a three-year-old boy with acute leukaemia), had an ear infection with resultant staphylococcal septicaemia and multiple abscesses which were localized in the spleen only, and the other patient (a 66-year-old diabetic with a mixed proteus and non-haemolytic streptococcal septicaemia from a foot infection) was found to have a large necrotic spleen abscess. McSherry and Dineen emphasized that the pathogenesis of splenic abscess was usually one of three formsmetastatic $(75 \%)$, posttraumatic $(15 \%)$, or contiguous infection usually from gastric or colonic lesions $(10 \%)$. With regard to splenic abscess as a result of contiguous infection, as well as McSherry and Dineen's case noted abnve, Kuiper et al. (1970) found among their records from 1936 to 1968 a previous case of isolated abscess secondary to a perforation of a gastric ulcer. Cultures grew Clostridium welchii. They also reported a case of splenic abscess due to Staphylococcus aureus, which they treated by splenectomy.

I wish to thank Mr. J. D. Jenkins, consultant surgeon and urologist, and Dr. J. M. Graham, consultant bacteriologist, for their helpful advice in the preparation of this case report.

\section{References}

British Medical fournal, 1971, 2, 347

Kuiper, Donald H., Lansing, East, Papp, John P., and Thompson, Norman W. (1970). Michigan Medicine, 69, 293.

McSherrv, C. K., and Dineen, P. (1962). American Fournal of Surgery, 103, 618.

Reid, S. E., and Lang, S. J. (1954). American fournal of Surgery, 88, 912 Vita, A., et al. (1969). Microbiologia, Parazitologia, Epidemiologia, 14, 53. 